\title{
Predictive Value of $C D 44$ for Prognosis in Patients with Breast Cancer
}

\author{
Yousef Roosta, Zohreh Sanaat*, Ali Reza Nikanfar, Roya Dolatkhah, Ashraf \\ Fakhrjou
}

\begin{abstract}
Background: Breast Cancer (BC), is one of the most common malignancies around the world. CD44 expression correlates with cell proliferation, infiltration, angiogenesis, metastasis and prognosis in breast cancer but the exact mechanism of CD44 function is still not clear. The present study evaluates the expression of CD44 in primary HER2-positive breast cancer. The results can be used to determine the disease-free and overall survival of patients with breast cancer. Methods: We studied specimens from 100 patients with HER2-positive invasive breast cancer between March 2011 and June 2019. Immunohistochemical staining for CD44 was performed in all the specimens. Their CD44 association with clinicopathologic parameters and prognosis was evaluated. Results: The high CD44 was expression in $68(68 \%)$ of the patients and Low expression in 32(32\%). CD44 expression was significantly associated with stage $(\mathrm{p}=0.007)$. There were no significant associations between the DFS, OS and other clinicopathologic parameters except for the stage, respectively $(\mathrm{HR}=3.67,95 \% \mathrm{CI}=1.16-11.56, \mathrm{P}=0.03)(\mathrm{HR}=0.8 .56,95 \% \mathrm{CI}=2.22-32.90, \mathrm{P}=0.002) .20 \%$ of patients had died by the end of the follow-up. There were no significant association between DFS, OS and CD44 expression, respectively. (Log-rank $p=0.13$ ). (Log-rank $p=0.10)$. Conclusion: The results from this study suggest that CD44 is clinically associated with stage of breast cancers. From the survival analysis, there was no statistical difference in overall survival and disease free survival with respect to $C D 44$ expression. Further studies larger sample sizes are recommended for further investigation.
\end{abstract}

Keywords: CD44- clinicopathological factors- breast cancer- HER2- Prognostic Factor

Asian Pac J Cancer Prev, 21 (9), 2561-2567

\section{Introduction}

The beginning of the $21^{\text {st }}$ century has been marked by intensified research on molecular genetics, epigenetics and the metabolic factors of cancer progression and treatment of patients (Chekhun et al, 2017).Breast cancer is now ranked the second most common malignancy(Jamel et al, 2010), the accounts for about 1.38 million new cases diagnosed every year (Ferlay et al, 2010).

Breast cancer is a highly heterogeneous disease with distinct biological and clinical behaviors and responses to treatment that can be classified into different subtypes based on histopathology type as well as molecular profile (Zhang et al., 2012; Hu et al., 2006).

Approximately $20-30 \%$ of breast cancer cases are HER2-positive owing to the over-expression and/or amplification of the HER2 gene (Dunnwald et al., 2007; Moasser et al., 2007). HER2-positivity is associated with aggressive clinical behaviors and poor clinical outcomes (Campone et al., 2011; Elster et al., 2015; Wange et al., 2003, Wange et al., 2012; Slamon et al., 1989).
Evidence suggests that some possible mechanisms for resistance to trastuzumab have been Cancer Stem Cells (CSCs), with ability to self-renew and differentiate and interfere with metastasis and contribute to chemo resistance and thus lead to tumor recurrence and relapse (Salmon et al., 1987; Rimawi et al., 2015). Recent observations showed that treatment with trastuzumab may directly affect BCSCs in HER2-positive breast cancer (Petrelli et al., 2012 ;Guo et al., 2015). In contrast, resistance to trastuzumab may be guided by BCSC (Petrelli et al., 2012; Guo et al., 2015). In 2003, Al-Hajj showed that tumorigenic breast cancer cells significantly exhibited stem cell-like properties, such as CD44+/CD24/low (Boulbes et al., 2015). The clinicopathological and prognostic significance of these findings is still controversial (Esteva, 2004; Swain et al., 2013).

CD44 is a Trans membrane glycoprotein molecule (gene is located on the chromosome $11 \mathrm{p} 13$ ) is widely expressed in the epithelial, mesenchymal and hematopoietic cells. Also, is involved in, division, survival, migration and adhesion of cells (Bedard et al., 2009). 
A correlation has also been reported between CD44 expression and Breast Cancer (BC) cell proliferation, infiltration, angiogenesis, metastasis and prognosis (Seo et al., 2016). Several studies have examined the relationship between CSCs and resistance to trastuzumab, resistance is indirectly guided by CSCs (Clarke and Fuller, 2006; Polyak and Hahn, 2006). Considering the importance of CSC markers for breast cancer and the recent evidence on HER2-positive breast cancer being treated with trastuzumab, which directly targets CSC. Although CD44 and HER2 are both negative predictors, it is still unclear whether they are related to each other. The present study thus evaluates the expression of $C D 44$ as a surrogate marker for BCSCs by immunohistochemistry in primary HER2-positive breast cancer. It further examines the association of $B C S C$ marker expression with the clinicopathological significance and prognostic value of HER2 positivity in breast cancer treated with trastuzumab. The results can be used to determine the disease-free and overall survival of patients with breast cancer.

\section{Materials and Methods}

\section{Patients and Samples}

This study was approved by the ethics committee of Tabriz University of Medical Sciences (under the code $5 / \mathrm{d} / 584008$ ) and all the patients signed an informed consent form at the time of referring to the study clinic which permitted the review of their medical records and tissue sample slides for future studies. The paraffin-embedded tumor tissues of 100 patients with invasive ductal carcinoma were available between March 2011 and June 2019 was analyzed in Tabriz University of Medical Sciences.

The archived slides of breast tumor tissue stained with hematoxylin and eosin were retrieved for all the cases and reviewed to confirm their pathological features based on the 2012 WHO classification (Kakarala and Wicha, 2008) .The suitable tissue blocks were identified for immunohistochemical (IHC) analysis.

The patients' medical records were reviewed for gathering their clinical data, including age at diagnosis, menopausal status, type of surgery, tumor size (T), histologic grade, axillary lymph node status (N),metastases status(M), tumor stage, lymphatic and neural and vascular invasion, estrogen receptor (ER) status, progesterone receptor (PR) status, P53, Ki-67, HER2 status and tumor recurrence or distant metastasis. All the patients received routine chemotherapy, endocrine and trastuzumab therapy following their surgery. Pathologic TNM classifica $\neg$ tion and staging were also performed for all the cases using the seventh edition of the American Joint Committee on Cancer Criteria (Li et al., 2008).

\section{Follow-up}

The overall survival (OS, in months) was measured based on all the occurred deaths regardless of their cause. Disease-free survival (DFS, in months) was defined as the time relapsed between the excisions of the primary tumor to the manifesta $\neg$ tion of local or distant metastasis.

\section{Immunohistochemistry Analysis}

IHC staining was performed in all the cases for ER, PR, HER2, Ki-67, P53 and CD44 biomarkers. For the histologic study, tumor samples were fixed in buffered formalin $10 \%$ and embedded as paraffin blocks. The sections were made from the formalin-fixed, paraffin-embedded blocks in four micrometers and were then deparaffinized in xylene and rehydrated in a graded series of alcohol $96 \%$ and 100\% solutions and then cooked with EDTA buffer at a $\mathrm{pH}$ of 6.0 at a sub-boiling temperature in three steps (each step taking $5 \mathrm{~min}$ ) and ultimately cooled for 20 minutes at room temperature. The sections were washed twice with Tris-Buffered Saline (TBS) for $10 \mathrm{~min}$. The sections were incubated in $\mathrm{H}_{2} \mathrm{O}_{2} 3 \%$ in methanol for $10 \mathrm{~min}$ to avoid tissue destruction. After the overnight incubation of CD44 ready to use antibody in $4^{\circ} \mathrm{C}$ refrigerator, the sections were detected with envision and chromogen. Afterwards, the slides were counterstained with Hematoxylin, dehydrated and then mounted. The following primary antibodies were used: ER (clone ID5; Dako Denmark A/S, Glostrup, Denmark), PR (clone PgR636; Dako Denmark A/S), Ki-67 (clone MIB-1; Dako Denmark A/S), P53 (cloneD07; Dako Denmark A/S), HER/2neu (REF: A0485, 1/200; Dako Denmark A/S) and CD44 (Clone: 156-3C11; HCAM, Diagnostic BioSystem, Pleasanton, CA, USA).The Haematoxylin and Eosin (H\&E) stain of breast sample and IHC stain for HER2, +3 Shown in (Figure 1 A , B). The Haematoxylin and Eosin (H\&E) stain of breast sample and IHC stain for HER2, +3 Shown in (Figure 1 A, B). CD44 immunostaining score was incorporated both staining intensity $(0=$ absent, $1=$ weak, $2=$ moderate, $3=$ strong $)$ and percentage of positive cells $(0=0 \%, 1=1-25 \%, 2=26-50 \%$, $3=51-75 \%$, $4=76-100 \%$ of cells). The immunostaining score was calculated based on the proportion of stained tumor cells: $0-10 \%$ as negative (-), $11-25 \%$ as slightly positive $(+), 26-50 \%$ as moderately positive $(++)$, and $51-100 \%$ as strongly positive $(+++)$. Patients with - and + expression was combined as the lower expression group, and patients with ++ and +++ expression was combined as the higher expression group for analyses (Tanei et al, 2009) (Figure 1 C, D).

\section{Statistical analysis}

CD44 expression was considered as binary independent factor (low and high level of CD44). The association between CD44 expressions and clinicopathologic parameters was examined with Chi-square test or Fisher's exact test. The Kaplan-Meier method was used to evaluate survival rates and log rank test was used to compare survival of patients with low and high level of CD44. The univariate Cox proportional hazard regression model was performed to observe the association of CD44 with survival rates. The multivariate Cox proportional hazard regression analysis was performed to assess association of CD44 with OS and PFS, adjusted for confounding variables (grade, tumor size, axillary node, metastases, stage, ER, PR and CD44 expression. The proportional hazard assumption was checked for Cox regression based on Schoenfeld residuals. Harrell's C-index was calculated to determine the predictive power of CD44 by Survival rates. The p-value $<0.05$ were considered significant. 
CD44 Expression Correlates with Cell Proliferation, Infiltration, Angiogenesis, Metastasis and Prognosis in Breast Cancer.

All the statistical analyses were performed in STATA, Version 14.

\section{Results}

Clinicopathological Features

The mean \pm SD age of the patients was $46.94 \pm 9.63$ years (range: $26-80$ years). About $67 \%$ of cases were younger than 50 years old.

Association between clinicopathologic parameters and CD44 expression

The high CD44 was expression in $68(68 \%)$ of the patients and Low expression in 32(32\%). CD44 expression was significantly associated with stage $(\mathrm{p}=0.007)$. There were no relationships between $C D 44$ expression and other clinicopathologic parameters (Table 1).

\section{Survival analysis based on CD44 expression}

Survival analysis was estimated using the Kaplan-Meier method. $20 \%$ of patients had died by the end of the follow-up. In $75 \%$ of quadrants of, on average $71 \%$ of patients were alive There were no significant association between $O S$ and CD44 expression (log-rank $\mathrm{p}=0.10$; Figure 2A). 5 patients (of the 80 live breast cancers) had relapsed by the end of the follow-up. In $75 \%$ of quadrants, on average $48.4 \%$ of patients were alive without any relapse. There were no significant association between DFS and CD44 expression (log-rank $\mathrm{p}=0.13$; Figure 2B).

\section{Association between patient outcome and CD44 expression}

The Univariate Cox regression analysis showed that a poor DFS was not association with CD44 expression $(\mathrm{HR}=0.5,95 \% \mathrm{CI}=0.25-1.20, \mathrm{p}=.14)$. The proportion hazard assumption was satisfied for DFS ( $p$-value $=0.44$ ). Harrell's-C index for DFS was 0.58. Also, the univariate Cox regression analysis showed that OS was not association with $C D 44$ expression $(\mathrm{HR}=0.48,95 \% \mathrm{CI}$ $=0.20-1.18, \mathrm{p}=0.11)$. The proportion hazard assumption was satisfied for OS (p-value $=0.50)$.

\section{Harrell's-C index for OS was 0.60}

After adjustment for other clinicopathologic parameters, cox-regression analysis showed that there were no significant associations between the DFS and $C D 44$ expression $(\mathrm{HR}=0.78,95 \% \mathrm{CI}=0.30-1.04$, $\mathrm{P}=0.61)$. Cox-regression analysis also revealed that a poor OS was not significantly associated with CD44 ( $\mathrm{HR}=0.85,95 \% \mathrm{CI}=0.29-2.50, \mathrm{P}=0.77)$. There were no significant associations between the DFS, OS and other clinicopathologic parameters except for the stage, respectively $(\mathrm{HR}=3.67,95 \% \mathrm{CI}=1.16-11.56, \mathrm{P}=0.03)$ $(\mathrm{HR}=0.8 .56,95 \% \mathrm{CI}=2.22-32.90, \mathrm{P}=0.002)$. (Table 2) Neural, vascular, and lymphatic variables were omitted from multivariate analysis of OS and DFS due to the Spars and over-estimation.
Table 1. Clinicopathologic characteristics of patients with breast cancer according to the CD44 level

\begin{tabular}{|c|c|c|c|c|}
\hline \multirow[t]{2}{*}{ Variables } & \multirow[t]{2}{*}{ Total } & \multicolumn{2}{|c|}{$\mathrm{CD} 44$} & \multirow[t]{2}{*}{$\mathrm{P}$ value } \\
\hline & & Low $(\%)$ & High $(\%)$ & \\
\hline \multicolumn{5}{|l|}{ Age } \\
\hline$<50$ & 67 & $22(32.8)$ & $45(67.2)$ & 0.8 \\
\hline$>=50$ & 33 & $10(30.3)$ & $23(69.7)$ & \\
\hline \multicolumn{5}{|l|}{ Grade } \\
\hline I & 14 & $4(28.60$ & $10(71.4)$ & $1^{*}$ \\
\hline II & 82 & $27(32.9)$ & $55(67.1)$ & \\
\hline III & 4 & $1(250$ & $3(75)$ & \\
\hline \multicolumn{5}{|l|}{$\mathrm{T}$} \\
\hline$<=2$ & 31 & $7(22.6)$ & $24(77.4)$ & 0.24 \\
\hline $2-5$ & 59 & $20(33.9)$ & $39(66.1)$ & \\
\hline$>5$ & 10 & $5(50)$ & $5(50)$ & \\
\hline \multicolumn{5}{|l|}{$\mathrm{N}$} \\
\hline Positive & 73 & $28(38.4)$ & 45 (61.6) & 0.25 \\
\hline Negative & 27 & $4(14.8)$ & $23(85.2)$ & \\
\hline \multicolumn{5}{|l|}{ M } \\
\hline Positive & 7 & $3(42.9)$ & $4(57.1)$ & $0.67 *$ \\
\hline Negative & 93 & $29(31.2)$ & $64(68.8)$ & \\
\hline \multicolumn{5}{|l|}{ Stage } \\
\hline $\mathrm{I}, \mathrm{II}$ & 71 & $17(23.9)$ & $54(76.1)$ & 0.007 \\
\hline III,IV & 29 & $15(51.7)$ & $14(48.3)$ & \\
\hline \multicolumn{5}{|c|}{ Lymphatic Invasion } \\
\hline Positive & 81 & $28(34.6)$ & $53(65.4)$ & 0.25 \\
\hline Negative & 19 & $4(21.2)$ & $15(78.9)$ & \\
\hline \multicolumn{5}{|c|}{ Neural Invasion } \\
\hline Positive & 74 & $25(33.8)$ & $49(66.20$ & 0.51 \\
\hline Negative & 26 & $7(26.9)$ & $19(73.1)$ & \\
\hline \multicolumn{5}{|c|}{ Vascular Invasion } \\
\hline Positive & 86 & $28(32.6)$ & $58(67.4)$ & 0.76 \\
\hline Negative & 14 & $4(28.6)$ & $10(71.4)$ & \\
\hline \multicolumn{5}{|l|}{ ER } \\
\hline Positive & 96 & $24(34.8)$ & 45 (65.2) & 0.4 \\
\hline Negative & 31 & $8(25.8)$ & $23(74.2)$ & \\
\hline \multicolumn{5}{|l|}{ PR } \\
\hline Positive & 64 & $22(34.4)$ & $42(65.6)$ & 0.5 \\
\hline Negative & 36 & $10(27.8)$ & $26(72.2)$ & \\
\hline \multicolumn{5}{|l|}{ P 53} \\
\hline Positive & 51 & $16(31.4)$ & 35 (68.6) & 0.9 \\
\hline Negative & 49 & $16(32.7)$ & $33(67.3)$ & \\
\hline \multicolumn{5}{|l|}{ Ki 67} \\
\hline Positive & 64 & $22(34.4)$ & $42(65.6)$ & 0.5 \\
\hline Negative & 36 & $10(27.8)$ & $26(72.2)$ & \\
\hline \multicolumn{5}{|l|}{ DFS } \\
\hline Alive & 75 & $21(28)$ & $54(72)$ & 0.13 \\
\hline Relapse & 25 & $11(44)$ & $14(56)$ & \\
\hline \multicolumn{5}{|l|}{ OS } \\
\hline Alive & 80 & $23(28.8)$ & $57(71.3)$ & 0.2 \\
\hline Death & 20 & $9(45)$ & $11(55)$ & \\
\hline
\end{tabular}

*Fisher's exact test; ER, estrogen receptor; PR, progesterone receptor, DFS, Disease Free Survival, OS, Overall Survival.

Asian Pacific Journal of Cancer Prevention, Vol 21 

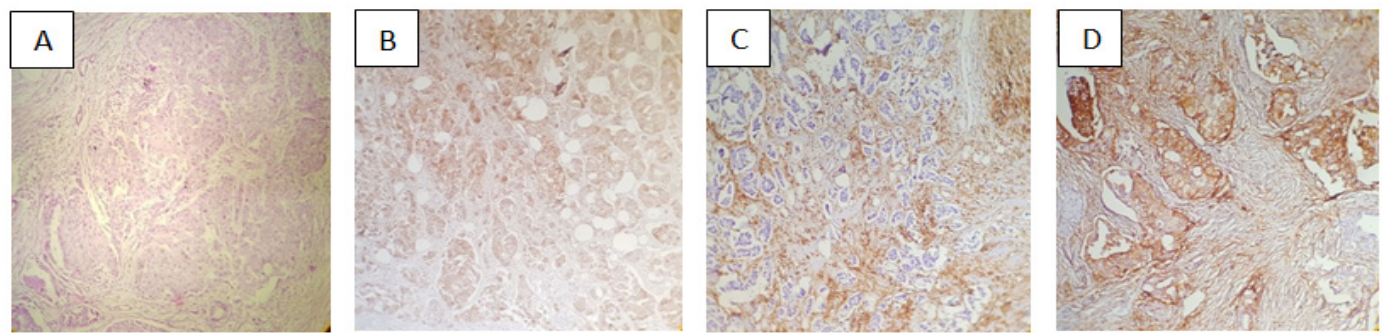

Figure 1. Immunohistochemical Analysis of CD44 in Breast Cancer(x100). Note : (A) Hemotoxylin and Eosin stain, (B) HER2 +3, (C) CD44 negative, (D) CD44 positive

Table 2. Hazard Ratios of CD44 for DFS and OS Adjusted for Clinicopathologic Characteristics of Patients with Breast Cancer (Multivariate Cox Proportional-Hazards Regression Model)

\begin{tabular}{|c|c|c|c|c|c|}
\hline \multirow[t]{2}{*}{ Variables } & & \multirow{2}{*}{$\begin{array}{c}\text { DFS } \\
\text { HR }(95 \% \mathrm{CI})\end{array}$} & \multirow[t]{2}{*}{$P$-value } & OS & \multirow[t]{2}{*}{$P$-value } \\
\hline & & & & HR $(95 \% \mathrm{CI})$ & \\
\hline \multirow[t]{3}{*}{ Grade } & I & Ref & & & \\
\hline & II & $3.31(0.41-26.50)$ & 0.25 & $2.73(0.32-23.16)$ & 0.35 \\
\hline & III & $4.90(0.23-101.72)$ & 0.3 & $4.60(0.20-106.52)$ & 0.34 \\
\hline \multirow[t]{3}{*}{$\mathrm{T}$} & $<=2$ & Ref & & & \\
\hline & $2-5$ & $0.40(0.15-1.13)$ & 0.08 & $0.55(0.18-1.74)$ & 0.31 \\
\hline & $>5$ & $0.52(0.11-2.40)$ & 0.4 & $0.20(0.03-1.17)$ & 0.07 \\
\hline \multirow[t]{2}{*}{$\mathrm{N}$} & Positive & Ref & & & \\
\hline & Negative & $0.65(0.19-2.20)$ & 0.5 & $0.94(0.22-3.40)$ & 0.93 \\
\hline \multirow[t]{2}{*}{ M } & Positive & Ref & & & \\
\hline & Negative & $0.31(0.09-1.09)$ & 0.07 & $0.75(0.20-2.88)$ & 0.7 \\
\hline \multirow[t]{2}{*}{ Stage } & $\mathrm{I}, \mathrm{II}$ & Ref & & & \\
\hline & III,IV & $3.70(1.16-11.60)$ & 0.03 & $8.60(2.22-32.90)$ & 0.002 \\
\hline \multirow[t]{2}{*}{ ER } & Positive & Ref & & & \\
\hline & Negative & $0.80(0.13-4.61)$ & 0.8 & $0.28(0.04-1.95)$ & 0.2 \\
\hline \multirow[t]{2}{*}{ PR } & Positive & Ref & & & \\
\hline & Negative & $2.51(0.50-13.54)$ & 0.3 & $4.08(0.70-24.62)$ & 0.12 \\
\hline \multirow[t]{2}{*}{$\mathrm{CD} 44$} & Low & Ref & & & \\
\hline & High & $0.80(0.30-2.04)$ & 0.61 & $0.85(0.30-2.50)$ & 0.77 \\
\hline
\end{tabular}

Notes: Lower, lower bound for 95\% CI; Upper, upper bound for 95\% CI; adjusted variables: Grade, Tumor size, Lymph node status, Metastases, Stage, ER, PR expression; ER, estrogen receptor; PR, progesterone receptor; DFS, disease free survival; OS, overall survival
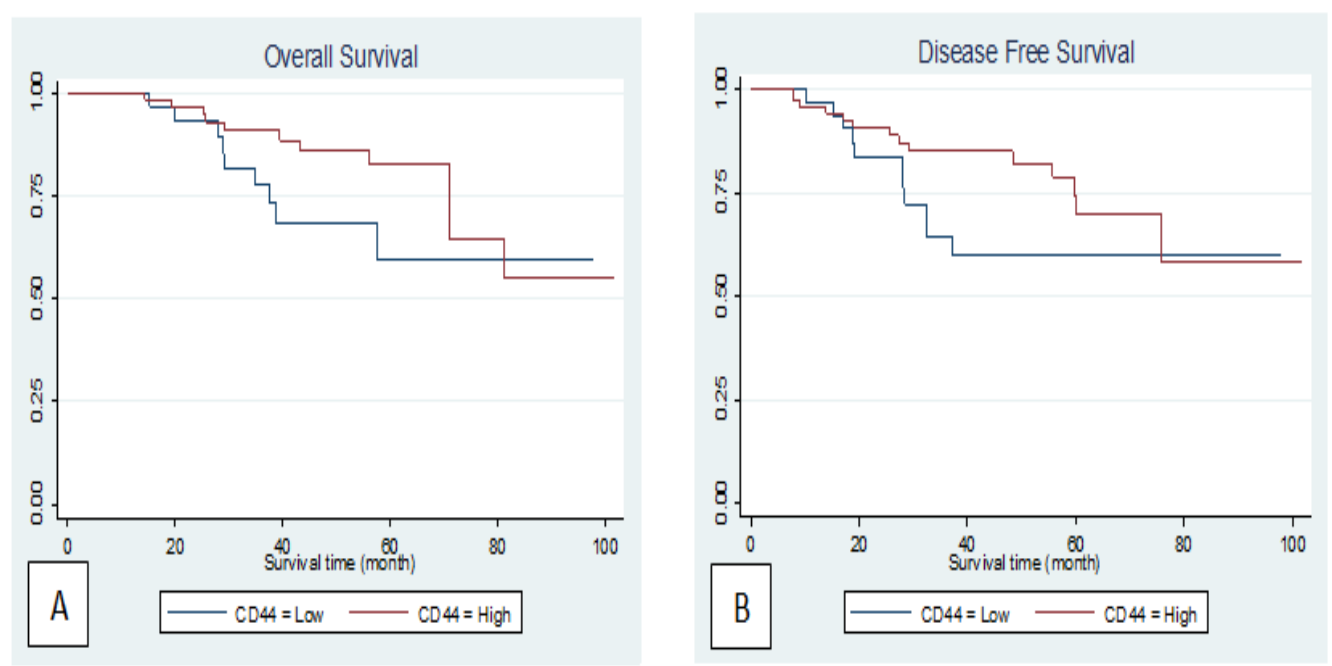

Figure 2. Kaplan-Meier Curves Showing association of CD44 Expression in Patients with Breast Cancer. (A) Overall Survival $(\mathrm{P}=0.10)$ and $(\mathrm{B})$, Disease-Free Survival $(\mathrm{P}=0.13)$

2564 Asian Pacific Journal of Cancer Prevention, Vol 21 


\section{Discussion}

Breast carcinoma is the leading cause of cancer death in women and is one of the most common malignancies in the world (Jemal et al., 2010). Breast cancer stem cells are a small population of cells that have the classic features of cancer stem cells and are transformed by the accumulation of mutations in the tumor cells (Jemalet al., 2010). The initial detection of breast cancer stem cells takes place based on the observation of a combination of CD44 and CD24 (Boulbes et al., 2015).

In this study, high CD44 was expression in $68(68 \%)$ of the patients and Low expression in $32(32 \%)$. CD44 expression was significantly associated with stage $(\mathrm{p}=0.007)$. There were no relationships between $C D 44$ expression and other clinicopathologic parameters. Since Al-Hajj et al., (2003) revealed for the first time that the tumorigenic stem cells in breast cancer have the CD44+, the tumorigenic potential and invasive features of this phenotype have been confirmed repeatedly (Mylona et al., 2008; Abraham et al., 2005) Olsson et al., (2011), Sanchez et al., (2001), Found that there are no significant associations between the CD44 expression and tumor size, lymph node status and hormone receptor. In our study we also did not find this association.According to the results obtained by Horiguchi et al., (2010), a higher expression of CD44 is significantly associated with a smaller tumor size, lack of axillary lymph node involvement and lower stages of breast cancer. In our study CD44 was associated just with higher stages. Bânkfalvi et al., (1998), observed that increased CD44 expression is associated with lymph node involvement in breast cancer. Looi et al., (2006), showed that CD44 plays an important role in the progression of breast cancer, CD44 expression increased in cases of breast cancer, which is associated with a high-grade tumor. These results contradict the present findings. Based on these disparate findings, there are probably several factors that may affect the expression of these markers in human breast cancer, including the use of different antibodies and conditions for immunohistochemistry (Olsson et al, 2011; Resetkova et al, 2010; Almed et al, 2012) CSCs are responsible for the initiation, progression and recurrence of various types of cancers, including breast cancer; however, we didn't find any significant association between $C D 44$ expression and clinical outcomes in this study. There were no significant differences between OS, $D F S$ and $C D 44$ expression (log-rank $\mathrm{p}=0.10$; Figure 2A; log-rank $\mathrm{p}=0.13$; Figure 2B).

Abraham et al., (2005), reported no significant relationships between the CD44+ phenotype and survival in patients with breast cancer, which is similar to the present findings. Other studies, such as those by (Mylona et al., 2008; Shipitsin et al., 2007; Kim et al., 2011; McFarlane et al., 2015), have suggested that CD44 expression is associated with a poor prognosis and can be considered a target for the treatment of breast cancer. The findings of those study and other studies cannot clearly elaborate the role of CSC in tumor.

In the present study, a poor DFS and OS was not association with $C D 44$ expression, respectively. ( $\mathrm{HR}=0.5$, $95 \% \mathrm{CI}=0.25-1.20, \mathrm{p}=.14),(\mathrm{HR}=0.85,95 \% \mathrm{CI}=0.29$ -
2.50, $\mathrm{P}=0.77)$.

The limitations of this research include the study of invasive breast cancer cases only. Camerlingo et al., (2014), and de Beca et al., (2013), examined the expression of CSC in various histological subtypes of breast cancer. Camerlingo did not report any association between histological subtype and the CD44 + phenotype, while De Beca et al., (2013) reported that modular, papillary and tubular carcinoma are expressed in the CD44+ phenotype. Second limitations of this research include the need for more patients with all breast cancer subtypes; third, the use of different types of antibodies and diverse conditions for immunohistochemistry; forth, not performing CD24 for economic reasons and evaluating CD44 only in the HER2-positive patients.

To the researchers' knowledge, the present research is the first effort in Iran to examine possible associations between CD44 and clinicopathological features and outcomes in HER2-positive breast cancer patients. The results showed that no significant associations were found between $C D 44$ expression and clinical outcomes in this study. Future studies need to verify these results using larger sample sizes and to investigate the association between CSC and clinicopathological features and prognostic parameters and their role in the treatment of breast cancer.

\section{Acknowledgments}

The authors wish to express their gratitude to the Hematology and Oncology Research Center for supporting this research (Grant No. 96/11). This study was conducted as part of a fellowship thesis by Dr. Rosta (Thesis No. 58304).

\section{Author Contributions}

YR provided substantial contributions to the conception and design of the manuscript, and the final approval of the version to be published, agreement to be accountable for all the aspects of the work in ensuring that any questions related to the accuracy or integrity of any part of the work are appropriately investigated and resolved.

AN contributed to the final approval of the version to be published, agreement to be accountable for all the aspects of the work in ensuring that questions related to the accuracy or integrity of any part of the work are appropriately investigated and resolved.

AF contributed to the IHC analysis, revising the article critically for important intellectual content, the final approval of the version to be published, agree-ment to be accountable for all the aspects of the work in ensuring that questions related to the accuracy or integrity of any part of the work are appropriately investigated and resolved.

$\mathrm{RD}$ contributed to the analysis and interpretation of the results, the final approval of the version to be published, and agreement to be accountable for all the aspects of the work in ensuring that questions related to the accuracy or integrity of any part of the work are appropriately investigated and resolved.

ZS provided substantial contributions to the conception and design of the manuscript, drafting the article, the final 
approval of the version to be published, and agreement to be accountable for all the aspects of the work in ensuring that questions related to the accuracy or integrity of any part of the work are appropriately investigated and resolved.

\section{Disclosure}

The authors report no conflicts of interest in this work.

\section{References}

Abraham BK, Fritz P, McClellan M, et al (2005). Prevalence of CD44+/CD24-/low cells in breast cancer may not be associated with clinical outcome but may favor distant metastasis. Clin Cancer Res, 11, 1154-9.

Ahmed M.A, Aleskandarany MA, Rakha EA, et al (2012). A CD44(-)/CD24(+) phenotype is a poor prognostic marker in early invasive breast cancer. Breast Cancer Res Treat, 133, 979-95.

Al-Hajj M, Wicha MS, Benito-HernandezA, Morrison SJ, Clarke MF (2003). Prospective identification of tumorigenic breast cancer cells. Proc Natl Acad Sci U S A, 100, 3983-8.

Bankfalvi A, Terpe HJ, Breukelmann D, et al (1998). Gains and losses of CD44 expression during breast carcinogenesis and tumour progression. Histopathology, 33, 107-16.

Bedard PL, Cardoso F, Piccart-Gebhart MJ (2009). Stemming resistance to HER-2 targeted therapy. J Mammary Gland Biol Neoplasia, 14, 55-66.

Boulbes DR, Chauhan GB, Jin Q, Bartholomeusz C, Esteva FJ (2015). CD44 expression contributes to trastuzumab resistance in HER2-positive breast cancer cells. Breast Cancer Res Treat, 151, 501-13.

Camerlingo R, Ferraro GA, De Francesco F, et al (2014). The role of CD44+/CD24-/low biomarker for screening, diagnosis and monitoring of breast cancer. Oncol Rep, 31, 1127-32.

Cancer Genome Atlas, N (2012). Comprehensive molecular portraits of human breast tumours. Nature, 490, 61-70.

Chekhun VF, Lukianova NY, Chekhun SV, et al (2017). Association of CD44(+)CD24(-/low) with markers of aggressiveness and plasticity of cell lines and tumors of patients with breast cancer. Exp Oncol, 39, 203-11.

Chen Y, Song J, Jiang Y, Yu C, Ma Z (2015). Predictive value of CD44 and CD24 for prognosis and chemotherapy response in invasive breast ductal carcinoma. Int J Clin Exp Pathol, 8, 11287-95.

Clarke MF, Fuller M (2006). Stem cells and cancer: two faces of eve. Cell, 124, 1111-5.

de Beca FF, Caetano P, Gerhard R, et al (2013). Cancer stem cells markers CD44, CD24 and ALDH1 in breast cancer special histological types. J Clin Pathol, 66, 187-91.

Du Y, Tao X, Wu J, et al (2018). APOBEC3B up-regulation independently predicts ovarian cancer prognosis: a cohort study. Cancer Cell Int, 18, 78.

Ferlay J, Shin HR, Bray F, et al (2010). Estimates of worldwide burden of cancer in 2008: GLOBOCAN 2008. Int J Cancer, 127, 2893-2917.

Giuliano AE, Connolly JL, Edge SB, et al (2017). Breast cancermajor changes in the American Joint Committee on Cancer eighth edition cancer staging manual. CA Cancer J Clin, 67, 290-303.

Guo W, Wang W, Zhu Y, et al (2015). HER2 status in molecular apocrine breast cancer: associations with clinical, pathological, and molecular features. Int J Clin Exp Pathol, 8, 8008-17.

Horiguchi K, Toi M, Horiguchi S, et al (2010). Predictive value of CD24 and CD44 for neoadjuvant chemotherapy response and prognosis in primary breast cancer patients. $J$ Med Dent Sci, 57, 165-75.

Hu Z, Fan C, Oh DS, et al (2006). The molecular portraits of breast tumors are conserved across microarray platforms. BMC Genomics, 7, 96.

Jemal A, Siegel R, Xu J, Ward E (2010). Cancer statistics, 2010. CA Cancer J Clin, 60, 277-300.

Kim HJ, Kim MJ, Ahn SH, et al (2011). Different prognostic significance of CD24 and CD44 expression in breast cancer according to hormone receptor status. Breast $J, 20,78-85$.

Li J, Zha XM, Wang R, et al (2012). Regulation of CD44 expression by tumor necrosis factor-alpha and its potential role in breast cancer cell migration. Biomed Pharmacother, 66, $144-50$.

Li X, Lewis MT, Huang J, et al (2008). Intrinsic resistance of tumorigenic breast cancer cells to chemotherapy. J Natl Cancer Inst, 100, 672-9.

Looi LM, Cheah PL, Zhao W, Ng MH, Yip CH (2006). CD44 expression and axillary lymph node metastasis in infiltrating ductal carcinoma of the breast. Malays J Pathol, 28, 83-6.

Martin-Castillo B, Oliveras-Ferraros C, Vazquez-Martin A, et al (2013). Basal/HER2 breast carcinomas: integrating molecular taxonomy with cancer stem cell dynamics to predict primary resistance to trastuzumab (Herceptin). Cell Cycle, 12, 225-45.

McFarlane S, Coulter JA, Tibbits P, et al (2015). CD44 increases the efficiency of distant metastasis of breast cancer. Oncotarget, 6, 11465-76.

Mylona E, Giannopoulou I, Fasomytakis E, et al (2008). The clinicopathologic and prognostic significance of CD44+/ CD24(-/low) and CD44-/CD24+ tumor cells in invasive breast carcinomas. Hum Pathol, 39, 1096-1102.

Olsson E, Honeth G, Bendahl PO, et al (2011). CD44 isoforms are heterogeneously expressed in breast cancer and correlate with tumor subtypes and cancer stem cell markers. $B M C$ Cancer, 11, 418.

Petrelli F, Barni S (2012). Role of HER2-neu as a prognostic factor for survival and relapse in $\mathrm{pT} 1 \mathrm{a}-\mathrm{bN} 0 \mathrm{M} 0$ breast cancer: a systematic review of the literature with a pooled-analysis. Med Oncol, 29, 2586-93.

Polyak K, Hahn WC (2006). Roots and stems: stem cells in cancer. Nat Med, 12, 296-300.

Resetkova E, Reis-Filho JS, Jain RK, et al (2010). Prognostic impact of ALDH1 in breast cancer: a story of stem cells and tumor microenvironment. Breast Cancer Res Treat, 123, 97-108.

Reya T, Morrison SJ, Clarke MF, Weissman IL (2001). Stem cells, cancer, and cancer stem cells. Nature, 414, 105-111.

Ricardo S, Vieira AF, Gerhard R, et al (2011). Breast cancer stem cell markers CD44, CD24 and ALDH1: expression distribution within intrinsic molecular subtype. J Clin Pathol, 64, 937-46.

Rimawi MF, Schiff R, Osborne CK (2015). Targeting HER2 for the treatment of breast cancer. Annu Rev Med, 66, 111-28.

Sanchez Lockhart M, Hajos SE, Basilio FM, Mongini C, Alvarez $\mathrm{E}$ (2001). Splice variant expression of CD44 in patients with breast and ovarian cancer. Oncol Rep, 8, 145-51.

Shipitsin M, Campbell LL, Argani P, et al (2007). Molecular definition of breast tumor heterogeneity. Cancer Cell, 11, 259-73.

Slamon DJ, Clark GM, Wong SG, et al (1987). Human breast cancer: correlation of relapse and survival with amplification of the HER-2/neu oncogene. Science, 235, 177-82.

Slamon DJ, Godolphin W, Jones LA, et al (1989). Studies of the HER-2/neu proto-oncogene in human breast and ovarian cancer. Science, 244, 707-12.

Tan PH, Ellis IO(2013). Myoepithelial and epithelial- 
myoepithelial, mesenchymal and fibroepithelial breast lesions: updates from the WHO Classification of Tumours of the Breast 2012. J Clin Pathol, 66, 465-70.

$\mathrm{Xu} \mathrm{H,} \mathrm{Wu} \mathrm{K,} \mathrm{Tian} \mathrm{Y,} \mathrm{et} \mathrm{al} \mathrm{(2016).} \mathrm{CD44} \mathrm{correlates} \mathrm{with}$ clinicopathological characteristics and is upregulated by EGFR in breast cancer. Int $J$ Oncol, 49, 1343-50.

Zhang ML, Huang ZZ, Zheng Y (2012). Estimates and prediction on incidence, mortality and prevalence of breast cancer in China, 2008. Zhonghua Liu Xing Bing Xue Za Zhi, 33, 1049-51.

\section{(ब) $(1)$}

This work is licensed under a Creative Commons AttributionNon Commercial 4.0 International License. 